\title{
ETHNIC REVIEW
}

\section{Access to health care for ethnic minority populations}

\section{A Szczepura}

Postgrad Med J 2005;81:141-147. doi: 10.1136/pgmj.2004.026237

This paper reviews the research evidence on access to health care by ethnic minority populations, and discusses what might need to be done to improve access to services. Research on the process of care, and the quality of care received, is considered as well as studies examining uptake of services. Changes in legal context are increasing the pressure on healthcare organisations to examine and adapt their services to ensure equitable access. Examples presented include a new UK population cancer screening programme. The main challenges for clinicians, managers, and policy makers in ensuring equitable access are discussed.

\section{Correspondence to: Professor A Szczepura, Division of Clinical Sciences, Warwick Medical School, University of Warwick, Coventry CV4 7AL, UK; chssas@wbs. warwick.ac.uk}

Submitted 29 June 2004 Accepted 12 August 2004 t most healthcare systems, it is acknowledged that black and minority ethnic (BME) populations have until now experienced poorer health and barriers to accessing certain services. Closing the health gap for people in these population groups is now an important priority. In the UK, as in other countries, the growth of various ethnic communities and linguistic groups, each with its own cultural traits and health profiles, presents a complex challenge to healthcare practitioners and policy makers in terms of achieving equitable access. This paper presents some of the research evidence on access by ethnic minority populations, and considers what might need to be done to improve the situation. The discussion is based on a number of reviews undertaken by the author examining the evidence on population diversity and variations in service uptake, health outcomes, effective patient communication, and involvement in decision making. ${ }^{1-4}$

At the same time, evidence of good practice is also beginning to emerge in some parts of the world. One of the largest BME populations is found in the USA, with nearly one in two Americans expected to be a member of a racial or ethnic minority group by $2050 .{ }^{5}$ Findings from the US 2000 census similarly show major health disparities, with "settled" groups such as black Americans and American Indians, as well as more recent immigrant groups such as Asians and Hispanics, at higher risk of missing the benefits of health care. As a result, the US Agency for Healthcare Research and Quality has recently been asked to produce an annual National Healthcare Disparities Report that will consider "disparities in health care delivery as it relates to racial factors" plus an annual National Health Care Quality Report; both reports will use a common framework because it is recognised that "disparities often present as inequalities in quality", in other words even if certain groups use a service they may still experience inferior quality care and, therefore, poorer access. ${ }^{6}$ The publication of these US reports provides the first comprehensive snapshot of disparities and quality of care for ethnic minority groups in the United States; performance measures underlying both reports will be used to monitor progress towards improved healthcare delivery for these and other disadvantaged groups. ${ }^{7}$

In the UK, a similar need to close the health gap for ethnic minorities is recognised by bodies such as the Department of Health and professional associations. Furthermore, after the implementation of the Race Relations Amendment Act 2000 in April 2001, a statutory duty has been laid upon the NHS and other UK public service agencies to "have due regard to the need to eliminate unlawful discrimination", and to ensure that every new action or policy considers the implications for racial equality. ${ }^{8}$ The NHS has, since April 1996, expected that all hospital trusts would record data relating to the ethnic origin of all "admitted patients" (including day cases). Although there has been a steady growth in collection of these data, levels of completion remain low, and this makes disparities in healthcare access difficult to monitor in the UK. Thus, a consistent message from the literature on access is the need for better ethnic monitoring data in the NHS, and for greater use to be made of these data to justify its collection. Low completion levels may partly be because of the perceived sensitivity of this area on the part of healthcare workers, ${ }^{9}{ }^{10}$ and also possibly because the information collected may be insufficiently detailed for clinical care and health service planning purposes. ${ }^{2}$

The slow implementation of ethnic monitoring data recording in the NHS means that, unlike the USA, it has not been possible to develop a UK overview of disparities in service access for BME populations or to monitor these nationally. ${ }^{7}$ At the same time, there is evidence from the 2001 and earlier censuses that health disparities exist in the UK and that levels of long term illness are higher in most BME groups than in the general population, especially for older age groups. ${ }^{11} 12$ Furthermore, in terms of service quality indicators, analysis of responses to the patient satisfaction surveys undertaken on behalf of the NHS shows distinct differences for ethnic minority groups. ${ }^{13}$ But, UK data on ethnic minority groups

Abbreviations: $B M E$, black and minority ethnic; $C R C$, colorectal cancer; FOBt, faecal occult blood test 
and disparities in health and quality of care has not been integrated, unlike the initiative set in motion by the Department of Health and Human Sciences in the USA.

Poor implementation of ethnic monitoring data recording in the NHS means that it has not been possible to develop a UK overview of disparities in service access or to monitor these nationally.

\section{UK POPULATION DIVERSITY}

The UK has a comparatively large BME population and this is gradually increasing in size. In the 2001 census, the BME population was $7.9 \%$ (or 4.6 million), having risen from a figure of $5.5 \%$ in 1991 and $4.2 \%$ in 1981. The south Asian group accounts for about half of this population (2 million people). There are also 1.15 million "black" people, including nearly 0.6 million from the more established "black Caribbean" population and nearly half a million "black Africans". These populations are more youthful in age structure than the white population, which means that ethnic minority population growth will remain rapid over the coming years.

The BME population is principally located in England, where 1 in 11 of the population is currently from such groups; just over half $(4.6 \%)$ are of south Asian origin (including Indian, Pakistani, and Bangladeshi groups), 2.3\% are of Caribbean and African origin, and the remainder of various origins including Chinese, Arabs, and "mixed" backgrounds. According to the 2001 census, nearly half $(45 \%)$ of the minority ethnic population lives in the Greater London area, where they form $29 \%$ of the population overall. A further $13 \%$ of the BME population is resident in the West Midlands. Certain minorities are even more concentrated in London-for example, $78 \%$ of the black African population lives in London, as does nearly two thirds of the Caribbean origin population $(61 \%)$. Information on certain ethnic minority groups such as asylum seekers and seasonal or migrant workers is more difficult to find. These groups are likely to be poorly recorded in sources such as the census and other national datasets (for example, Labour Force Survey, for migrant workers). However, estimates are available of the numbers of refugees and asylum seekers in London ${ }^{14}$; and research also highlights issues relating to their access to health and services. ${ }^{15}$ In contrast, there is little information available on seasonal and migrant workers or their health needs, although clearly this group will become increasingly important as the UK encourages such workers, especially from other parts of the EU and eastern Europe.

\section{ACCESS TO HEALTH CARE COMPARED WITH SERVICE PROVISION}

Appropriate access to health care for a diverse population requires more than simply providing the service. Provision alone cannot ensure access to care for all people, regardless of their religion, culture, or ethnic background. This has recently been acknowledged in the NHS, as has the requirement for a major re-think of concepts previously held about access to services by BME groups:

Diversity is a fairly new word in Britain. Prior to recognition of diversity, the idea was that some services for black and minority ethnic groups could be provided, but the quality of services and whether they reached the population was not an issue. When black and minority ethnic groups raised the issue of services not reaching them, the standard answer was, "but we are providing the services of a link worker or an advocate and we are meeting your religious and cultural needs."16

The same author had previously in 1996 identified a need for improvements in access to cancer screening and treatment programmes for ethnic minorities, when presenting the Department of Health's perspective on these services:

\begin{abstract}
"The Government's 'Health of the Nation' report produced in 1993 by the Department of Health identifies key areas, including cancer, where improvements in mortality and morbidity could be achieved, and an essential element relates to the needs of black and minority ethnic people. It is, for example, now well recognised that in terms of screening, treatment and palliation, cancer services are not always accessible and sensitive to the needs of this section of the population. ${ }^{\prime \prime 15}$
\end{abstract}

A recent review on access to, and uptake of, NHS services by ethnic minorities ${ }^{2}$ has identified the following three dimensions of equitable access:

- having equal access via appropriate information;

- having access to services that are relevant, timely, and sensitive to the person's needs;

- being able to use the health service with ease, and having confidence that you will be treated with respect.

In summary, access is clearly linked to equal care, as it is accepted that "access-related factors may be the most significant barriers to equitable care" ${ }^{\prime 7}{ }^{18}$ Equitable access has been defined as "care that does not vary in quality because of personal characteristics, such as gender, ethnicity, geographical location and socio-economic status". ${ }^{19}$ Adequate access is also linked to timeliness and the quality of services, as exemplified by definitions such as "the timely use of personal health services to achieve the best health outcomes". ${ }^{20}$ Thus, definitions of "access" that are limited to service uptake or "receipt of care" are clearly inadequate unless they also consider the process of accessing care, and the quality of care received by ethnic minority groups.

Definitions of "access" that are limited to service uptake or "receipt of care" are clearly inadequate unless they also consider the process of accessing care, and the quality of care received by ethnic minority groups.

\section{LINGUISTIC AND CULTURAL COMPETENCE}

In countries and regions that have experience of population diversity (especially the USA, Australia, Canada, and also the United Kingdom) consideration is now being given to developing linguistic and cultural competence in healthcare organisations. In particular, it is acknowledged that, in a range of clinical areas where access is shown to be poor, healthcare services now need to develop policies and structures to begin to tackle such disparities. Policies should focus on both linguistic and cultural competence; and they should have the capacity to adapt to the changing cultural contexts of the communities served. 
Extensive evidence is emerging on the need for cultural competence, as well as linguistic competence, in healthcare organisations.

\section{Linguistic competence}

Linguistic competence describes the capacity of an organisation and its personnel to communicate effectively, and convey information in a manner that is easily understood by diverse audiences including persons of limited English proficiency, and those who have low literacy skills or are not literate. $^{21} 22$ This is clearly of key importance in ensuring equitable access for many ethnic minority populations. Improved access for such populations might require provision of: bilingual/bicultural staff; foreign language interpreting services; link workers/advocates; materials developed and tested for specific cultural, ethnic, and linguistic groups; translation services including those of: (a) legally binding documents (for example, consent forms), (b) hospital signage, (c) health education materials, (d) public awareness materials and campaigns; and ethnic media in languages other than English, for example, television, radio, internet, newspapers, periodicals.

\section{Cultural competence}

Although language barriers may be important, it is also well reported that various dimensions of culture can influence successful healthcare delivery to ethnic minority populations. ${ }^{21}$ Cultural differences are also likely to be more persistent than language needs in immigrant groups. Cultural dimensions might include:

- patients' health, healing, and wellness belief systems;

- how illness, disease, and their causes are perceived;

- the behaviour of patients/consumers seeking health care, and their attitudes toward healthcare providers;

- the views and values of those delivering health care.

Thus, healthcare organisations and their staff need to be culturally as well as linguistically competent. Improved responsiveness to the health beliefs, practices, and cultural needs of patients is clearly required to provide equitable access to healthcare services for diverse populations. Such provision should also recognise that the provider and the ethnic minority patient each bring their own individual learned patterns of language and culture to the healthcare experience.

Appropriate access to health care requires more than simply providing a service. Provision alone does not ensure access for all people, regardless of their religion, culture, or ethnic background.

\section{STUDIES OF DISPARITY IN ACCESS TO HEALTH CARE FOR ETHNIC MINORITY POPULATIONS}

Reviews of evidence on the use of NHS services by ethnic minorities would seem to provide evidence of the presence of access problems. ${ }^{23}$ However, the findings may not be conclusive. For example, studies often rely on receipt of care or uptake levels as a measure of access, and this does not allow for variations in levels of need in different populations. ${ }^{19}$ Also, studies of access should ideally control for income and other social factors to check whether the differences in uptake observed might be explained by factors other than ethnicity. Even though there are comparatively few rigorous studies of this type, it is generally accepted that ethnic differences in access to health services cannot simply be reduced to socioeconomic factors. ${ }^{24}$

Examination of the research literature on access identifies a consistent pattern in most disease areas in terms of the evidence available. ${ }^{2}$ Most articles focus on the differential uptake of services or receipt of care; there are fewer papers reporting research on process, including barriers to accessing care and factors influencing these; and there is very little peer reviewed literature on the evaluation of interventions to improve access. The latter group are found mainly in the "grey" literature.

Ethnic differences in access to health services cannot simply be reduced to socioeconomic factors.

The available evidence thus falls into three main categories, and provides different types of evidence as follows.

\section{Quantitative analyses of uptake or receipt of care}

Such research can show apparent inequalities and raise questions about the causes of these, using methods such as secondary analysis of data collected for other purposes, ${ }^{25}$ or questionnaire based surveys. ${ }^{26-28}$ These studies do not usually offer an explanation, but they can flag up the presence of disparities that require further investigation.

Analysis of uptake figures can show apparent inequalities and raise questions about the causes of these.

\section{Process oriented research}

This can provide potential explanations, often using focus groups or semi-structured interviews to explore possible reasons for any disparities identified through quantitative analyses. ${ }^{29}$ By identifying barriers to access, such research can also build up an evidence base for possible intervention studies. Yet other studies in this area present descriptions of "good practice" (for example, Bowes and Domokos ${ }^{30}$ and $\left.S^{S h a h}{ }^{31}\right)$. Although such research does not usually provide evidence of effectiveness, it can once again provide evidence for the types of interventions that might be worth evaluating, as well as showing their feasibility. It is perhaps significant that most of the literature reporting process oriented research comes to a similar conclusion, namely the essentially rational behaviour of patients, and the need for evaluation of interventions to improve access.

\section{Intervention studies}

This research requires the actual implementation and assessment of interventions designed to improve access and uptake. Such studies form a small minority of published studies on access. Where such research has been undertaken very few, if any, studies consider the cost or the cost effectiveness of the interventions evaluated. Some research has been undertaken to estimate the cost of providing interpreter, advocacy, and translation services, and this has been used to allocate some resources to different areas in the NHS. ${ }^{4}$ 
By identifying barriers to access, researchers can build up an evidence base for possible intervention studies. At present, there are very few intervention studies and virtually none consider the costs or cost effectiveness of interventions.

\section{FACTORS INFLUENCING ACCESS TO HEALTH CARE BY ETHNIC MINORITY GROUPS}

Explanations offered by researchers for reported disparities in access to health services fall into two main groups. The first group are linked to intrinsic or "personal" factors; these include the particular needs of ethnic minority people that must be met as part of ensuring equitable access. The second group are associated with extrinsic or organisational factors; these focus on the organisation itself and its healthcare delivery and planning systems.

\section{Intrinsic or personal factors \\ Cultural differences}

This is offered as a key explanation for disparities in access to health services by BME populations. This explanation recognises that people identify themselves with a social group on cultural grounds, and that diverse racial and ethnic groups may respond differently because of their particular health beliefs and behaviours. ${ }^{32}$ Cultural dimensions highlighted include: religion that may affect compliance or access to services; sex, which is commonly mentioned as an obstacle to service access by women; differential presentation including "somatisation" of symptoms, which is reported to lead to misunderstandings, misdiagnosis, or incorrect referrals; "fatalism" or shyness, which may also lead to a reluctance to seek help resulting in late presentation; and other cultural factors such as family dynamics may mean people cannot easily attend or take up services without the support of family members. ${ }^{2}$ It is recognised also that health professionals need to take into account these types of cultural beliefs and values when communicating with patients or users. ${ }^{33}$ Linked to this, there may be a need for visual representation (that is, pictorial reference to ethnic groups, cultures) in posters and other healthcare materials.

\section{Language and literacy}

Clearly poor linguistic competence will be a major barrier to access for some people. In such cases interpreting services are required to adequately diagnose, consent, and treat these people. This can be a complex organisational task. ${ }^{1}$ For example, recent surveys show that over 300 languages are used in London homes. ${ }^{34}{ }^{35}$ Furthermore, high levels of need seem to exist among UK adults, with only $14 \%$ of Bengalis, $29 \%$ of Gujeratis, $26 \%$ of Punjabis, $41 \%$ of Chinese, and 32\% of refugees reported to have a survival level of competence in the use of English in 1996. ${ }^{36}$ In the most populous south Asian groups in the UK (Indian, Pakistani, Bangladeshi) there is also good evidence that ability to speak English is lower for women than men, is much poorer for those born outside the UK, and declines with increasing age. ${ }^{37-39}$ Differences in literacy might be another important factor. Firstly, although people may be able to speak English they might not be able to read it. Estimates differ but there is general agreement that fewer than one third of older Bangladeshi and Pakistani women (50-75 years of age) can read English; and fewer than two thirds of older men. ${ }^{37} 38$ Another study has estimated that fewer than half of south Asian adults can read a school timetable or telephone directory. ${ }^{36}$ Furthermore, even if letters or patient information leaflets are translated, people may not be able to read their own language. Over half of older Bangladeshi and Pakistani women are illiterate in any language, and about
$20 \%$ of older men. ${ }^{37}$ In some cases, there may be no written form of their own language (for example, this is the case for Sylhetti, which more than one in two "over 50s" of Bangladeshi origin report as their main language). ${ }^{37}$

Poor linguistic competence is an important barrier to access for many with high levels of need among older ethnic minority adults.

\section{"Newness" or user ignorance}

This factor is related to the migrant status of people in the BME population, and shows itself through unfamiliarity with the NHS and limited knowledge of available services. Additional dimensions such as the lack of "grandparenting" within the social group (that is, family, friends, or other networks providing expert advice) are also identified as important. User ignorance has been offered as an explanation for patterns of poor access to services reported for new populations as they first come into contact with different forms of health care. For example, much of the initial literature on user ignorance in the UK was linked to studies of access to antenatal care and obstetric care, ${ }^{4041}$ and subsequently to low uptake of services for older people. ${ }^{42-46}$

\section{Extrinsic or organisational factors}

\section{Differential needs and provision}

In some cases, barriers to access may be linked to poor provision of certain services required specifically for ethnic minority groups. In the UK, this might include services for "ethnic" diseases such as haemoglobinopathies-that is, sickle cell disease among people of West African origin and West Indian descent, and thalassaemia among populations of south Asian and Mediterranean origin. ${ }^{47} 48$ Access to such "minority" services may be poor because they are not required by the majority white population and therefore provision is poor. ${ }^{49}$ In other cases, low levels of uptake of services (and apparent poor access) may be attributable to the relative rarity of certain diseases in ethnic minority populations (for example, cystic fibrosis). Both examples are linked to variations in the level of need for certain services in ethnic minority populations. However, even where need seems to be low, service provision should take account of the fact that diverse populations may still be at risk, ${ }^{3}$ and also that their risk profile may change over time, especially for conditions that are linked to lifestyle and environmental factors as well as genetic makeup. ${ }^{50}$

\section{Location}

The location of health services may result in poor access for certain mobile populations (for example, traveller gypsies, refugees, etc). Also, as settled ethnic populations move, for example through the process of suburbanisation, there may be a lag in providing appropriate services (for example, advocacy/link workers) in these new locations. ${ }^{2}$ Isolated minorities in areas not equipped to meet their language needs may also experience barriers in accessing routine services; for example, because of poor levels of interpreting provision in accident and emergency departments. ${ }^{51} 52$

\section{Staff training needs}

Finally, healthcare staff may have strong stereotypical views, lack cultural awareness, and ability, or generally manage patients from diverse backgrounds in an unsuitable manner, which can create barriers and generate resentment. The literature suggests that institutional racism should be tackled as part of any intervention to improve access for ethnic 
minority users. In addition, healthcare organisations may need to improve the diversity of their workforce, something that cannot be achieved by merely recruiting more ethnic minority individuals; it is recognised that diversity training for the existing majority workforce should be an integral part of this activity. ${ }^{534}$ Other forms of training may also be required. For example, the training of clinicians to recognise key symptoms, for example, sickle cell crisis ${ }^{48}$; administrative training to cope with distinctive naming systems; ; and last, but not least, training in the use of interpreters. ${ }^{55} 56$

\section{A CASE EXAMPLE: ACCESS TO NHS POPULATION CANCER SCREENING PROGRAMMES}

One example of poor access to health care by BME populations, and the need for policies and structures to tackle this, is that provided by cancer screening programmes in the UK.

\section{Cervical and breast cancer screening}

The two existing UK cancer screening programmes (cervical and breast) have consistently shown low uptake by ethnic minority groups over a number of years, particularly for south Asians. Hoare reviewed the UK evidence on uptake of breast cancer screening in 1996 and showed lower uptake among ethnic minority women. ${ }^{57}$ There is similar evidence of lower uptake of cervical cancer screening by south Asian women (Indian, Pakistani, and Bangladeshi), although uptake in the African Caribbean population has been reported to be high. ${ }^{58}$ Furthermore, UK studies that have compared cervical and breast cancer screening in diverse populations consistently show that breast screening uptake is lower. ${ }^{59} 60$

The four main reasons identified by researchers for low uptake in both programmes seem to be a lack of knowledge among women from the ethnic communities about screening services; language barriers; inaccurate screening registers, including poor awareness of minority ethnic naming systems, compounded for Asian women by extended visits to the Indian subcontinent; and a lack of referral/recommendations by healthcare professionals and physicians. Early articles (from 1991 onwards) on cervical cancer screening identified administration, language needs, and poor knowledge of the screening service as important barriers. ${ }^{61-64} \mathrm{~A}$ more recent (1999) paper also highlighted professional perceptions and poor communication. ${ }^{64}$ Furthermore, as might be expected, cervical cancer screening rates seem to be more strongly associated with practice characteristics than do breast screening rates; for example, cervical smear uptake rates are higher in practices with a female partner, ${ }^{62}$ although a similar effect is not apparent for breast screening. ${ }^{65}$ For breast cancer screening, early research (from 1992 onwards) similarly identified poor health information, errors in the screening register, and lack of knowledge of screening as important factors. ${ }^{66-68}$ Later papers continued to report lack of knowledge ${ }^{59}$ plus the need for active physician encouragement $t^{65}$ as important factors. Research has also highlighted the need for more attention to broader questions of power relations ${ }^{64}$ and indirect discriminations. ${ }^{67}$ At the same time, some early research did report comparable uptake of cervical cancer screening among south Asian women. ${ }^{69}$ However, more recent research (2001) seems to show that the disparities in uptake of both cervical and breast cancer screening observed earlier have not yet been rectified. ${ }^{70}$

Although there is considerable literature on disparities in screening uptake, there is little research reporting attempts to improve access to cancer screening for ethnic minority populations. The UK literature reports only one trial for cervical cancer screening; this found that home visits were more effective than a postal leaflet, with some evidence that home viewed videos may be particularly effective in one of the most hard to reach groups, Urdu speaking Pakistani
Moslems. ${ }^{71}$ Slightly more UK trials of interventions to improve breast cancer screening uptake have been reported. Based on these, it would seem that the use of a reminder letter has only a limited role in improving uptake. ${ }^{72}{ }^{73}$ Unlike cervical cancer screening, there also seems to be no evidence that home visits by an NHS linkworker are effective in improving access to mammography. ${ }^{74}{ }^{75}$ However, there is some evidence that training practice receptionists to follow up non-attendees can have a significant effect (55\% compared with $31 \%, \mathrm{p}<0.01) .{ }^{76}$ International studies provide similar evidence on potential interventions to increase cervical cancer screening uptake by ethnic minorities. A limited positive impact has been reported from the USA for linkworkers, ${ }^{77-78}$ and little benefit has been observed from translated reminder letters in Australia. ${ }^{79} 80$

However, there does seem to be some consistent evidence to show that complex, multi-strategies are able to improve uptake of cancer screening by ethnic minority groups. ${ }^{76} 8182$ Such interventions might include practice receptionist training, follow up letters in various languages, offers of transport, health advocates on site, and (for breast screening) mobile units available for longer. A similar sized positive impact has been reported by several of these studies (with initial uptake rising from about $30 \%$ to $50 \%$ ). None of these studies has considered cost or cost effectiveness.

From the research discussed above, it is apparent that the evidence of poor levels of uptake by south Asians for the two existing cancer screening programmes has been available for some time. However, little research has been carried out to identify effective interventions to improve access in these population groups.

\section{Colorectal cancer screening}

The NHS is currently considering the introduction of a new population cancer screening programme; colorectal cancer (CRC) screening using a self administered faecal occult blood test (FOBt), followed by colonoscopy for those who screen positive. Colorectal cancer is the second most common cause of all cancer deaths in the UK, with five year survival of about $40 \%$ and 16170 deaths in $2001 .{ }^{83}$ In 2000, the UK National Screening Committee established a pilot to assess the feasibility of introducing this third cancer screening programme. ${ }^{84}$ At that time there was no evidence on probable CRC screening uptake levels for UK ethnic minority population groups. The original Nottingham trial of FOBt screening did not record uptake by ethnic group, ${ }^{85}$ and a subsequent trial of mass screening by flexible sigmoidoscopy had also not provided any data on ethnic uptakes. ${ }^{86}$

However, in the USA uptake of CRC screening by ethnic minority groups is reported to be even lower than uptake of breast and cervical cancer screening. ${ }^{87}$ Similarly, a Swedish study of CRC screening in a diverse population has identified lower uptake levels among older (age >64 years) immigrants; with uptakes of $44 \%$ compared with $69 \%$ for the whole age group. ${ }^{88}$ Research emerging from the USA has consistently identified lower FOBt uptake levels for a range of ethnic minority groups, both in established populations such as African Americans ${ }^{89-92}$ and in more recent immigrant populations, including Koreans, Japanese, Chinese, and south east Asians. ${ }^{93-95} \mathrm{~A}$ few studies have separated sociodemographic characteristics (for example, income or education level) from ethnic diversity, and found that sociodemographic factors cannot fully explain the observed variations in uptake, especially for older people. ${ }^{87}$

Most US studies conclude that interventions should be developed to increase knowledge, improve risk perception, and facilitate access to CRC screening for minority populations, but there remains little or no research examining what form of intervention might be most effective or cost effective. ${ }^{96} 97$ 


\section{Key references}

- Atkinson M, Clark M, Clay D, et al. Systematic review of ethnicity and health service access for London. Coventry: Centre for Health Services Studies, University of Warwick, 2001

- Szczepura A, Johnson M, Gumber G, et al. A review of the research evidence on ethnicity and communication. Coventry: Centre for Health Services Studies, University of Warwick, 2004.

- Smedley BD, Stith AY, Nelson AR, eds. Unequal treatment: confronting racial and ethnic disparities in health care. Washington, DC: National Academies Press, 2003.

- Audit Commission. What seems to be the matter: communication between hospitals and patients. Audit Commission report. London: HMSO, 1994.

- US National Center for Cultural Competence. http:// www.omhrc.gov/omh/programs/2pgprograms/ finalreport.pdf

In summary, the introduction of CRC screening in the UK will represent a major challenge in terms of ensuring equitable access for BME populations. Preliminary analysis of data from the UK pilot shows very low uptake by south Asians. ${ }^{98}$ Uptakes are particularly low for Muslims and Sikhs; both groups include red meat eaters and are therefore at greater risk of colorectal cancer than the other mostly vegetarian south Asian groups. Even if other demographic factors (age, sex, and deprivation) are taken into account in a multivariate analysis, the ethnic minority populations continue to exhibit particularly poor uptakes. Research from other countries on barriers to uptake of CRC screening by ethnic minorities identifies older age,,$^{87-92} 99$ and shorter acculturation or length of residence ${ }^{81} 100101$ as significant predictors of low FOBt uptake, both of which may be related to cultural and language needs.

\section{CONCLUSIONS}

A substantial research base now exists to show disparities in access to healthcare services for ethnic minority populations in different parts of the world. Healthcare organisations and their staff need to be culturally, as well as linguistically, competent when delivering services. Improved responsiveness to the health beliefs, practices, and cultural needs of patients is clearly required to provide equitable access to health care for diverse populations. Such provision should also recognise that the provider and the ethnic minority patient each bring their own individual learned patterns of language and culture to the healthcare experience.

In conclusion, ensuring equitable access to healthcare services by ethnic minorities will represent a major challenge for clinicians, managers and policy makers in the coming decades. At the same time, it is clear that the changing legal context in countries like the UK after the Race Relations Amendment Act 2000, and in the remainder of Europe after Human Rights legislation, increases the pressure on healthcare organisations to examine and adapt services to ensure equitable access for local ethnic minority populations. The example presented, of a new UK CRC screening programme, serves to show the paucity of evidence on interventions to assure access for ethnic minority populations. Finally, to fully address issues of access, inequalities in the quality of care received, as well as disparities in uptake of care, need to be examined and addressed.
After the implementation of the Race Relations Amendment Act 2000, the NHS must consider the implications for racial equality of every action or policy. Access to services should be viewed in the context of this major new requirement.

\section{REFERENCES}

1 Szczepura A, Johnson M, Gumber G, et al. A review of the research evidence on ethnicity and communication. Coventry: Centre for Health Services Studies, University of Warwick, 2004.

2 Atkinson M, Clark M, Clay D, et al. Systematic review of ethnicity and health service access for London. Coventry: Centre for Health Services Studies, University of Warwick, 2001.

3 Johnson MRD, Clark MD, Owens D, et al. The unavoidable costs of ethnicity: a review of evidence on health costs. Coventry: Centre for Health Services Studies, University of Warwick, 1999.

4 Szczepura A, Clark MD, Johnson MRD, et al. Assessment of the costs to the NHS arising from the need for interpreter, advocacy and translation services. Coventry: Centre for Health Services Studies, University of Warwick, 1999.

5 US Bureau of the Census. Population projections of the United States by age, sex, race, and Hispanic origin: 1995 to 2050 . Current Population reports, no P25-1130. Issued February 1996; revised April 1999. http:// www.census.gov/prod/1/pop/p25-1130.

6 Swift EK, ed. Guidance for designing a national healthcare disparities report. Washington, DC: National Academies Press, 2002.

7 Committee on National Statistics. Eliminating health disparities. Washington, DC: The National Academies Press, 2004.

8 Parliament. Race Relations (Amendment) Act 2000: Elizabeth II: chapter 34. London: Stationery Office, 2000

9 Bhatti-Sinclair K, Wheal A. Analysis of the external audit on ethnically sensitive practice. J Clin Effect 1998;3:6-9.

10 Bhatti-Sinclair K, Wheal A. Using external audit to review ethnically sensitive practice. J Clin Effect 1998;3:2-5.

11 Szczepura A, Gumber G, Clay D, et al. Review of the occupational health and safety of Britain's ethnic minorities. Research Report 221. Norwich: Health and Safety Executive, 2004.

12 Owen D. Ethnic minorities in Great Britain: housing and family characteristics, 1991 census statistical paper 4. Coventry: Centre for Research in Ethnic Relations National Ethnic Minority Data Archive, 1993.

13 Commission for Health Improvement. Unpacking the patient's perspective: variations in NHS patient experience in England. London: CHI, 2004.

14 Storkey M, Bardsley M. Estimating the numbers of refugees and asylum seekers in London. In: Aldous J, Bardsley M, Daniell R, et al. Refugee health in London: key issues for public health. London: Health of Londoners Project, 1999: 11-26.

15 Aldous J, Bardsley M, Daniell R, et al. Refugee health in London: key issues for public health. London: Health of Londoners Project, 1999.

16 Bahl V. Improving access and quality for ethnic minority women. Womens Health Issues $2001 ; 11: 348-54$.

17 Bahl V. Cancer and ethnic minorities: the Department of Health's perspective. Br J Cancer 1996;74:S10.

18 Smedley BD, Stith AY, Nelson AR, eds. Unequal treatment: confronting racial and ethnic disparities in health care. Washington DC: National Academies Press, 2003.

19 Millman M, ed. Access to health care in America. Washington, DC: National Academy Press, 1993

20 Fiscella K, Franks P, Gold MR, et al. Inequalities in quality: addressing socioeconomic, racial, and ethnic disparities in health care. JAMA 2000;283:2579-84.

21 US National Center for Cultural Competence. http://www.omhrc.gov/ omh/programs/2pgprograms/finalreport.pdf.

22 Anderson LM, Scrimshaw SC, Fullilove MT, et al. Culturally competent healthcare systems. A systematic review. Am J Prev Med 2003;24:68-79.

23 Smaje C, Le Grand J. Ethnicity equity and the use of health services in the British NHS. Soc Sci Med 1997;45:485-96.

24 Davey Smith G. Ethnicity, socio-economic position and health. ESRC Health Variations Newsletter 2000;6.

25 Gill P, Scrivener G, Lloyd D, et al. The effect of patient ethnicity on prescribing rates. Health Trends 1995;27:111-13.

26 Leisten R, Richardson J. Access to health: a minority ethnic perspective. Northampton: BHA/Nene College, 1994.

27 Richardson J, Leisten R, Calviou A. Lost For words. Health services are inaccessible to many people from ethnic minorities because of inappropriate health information. Nursing Times 1994;90:31-3.

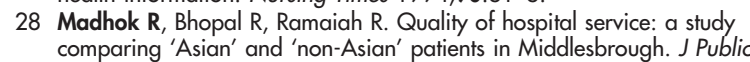
Health Med 1992;14:271-9.

29 Sheldon H. Consulting with local black and minority ethnic groups. London: Lewisham Hospital NHS Trust, 1996.

30 Bowes A, Domokos T. Health visitors' work in a multi-ethnic society: a qualitative Study of social exclusion. Journal of Social Policy 1998;27:498-506.

31 Shah R. Improving services to Asian families and children with disabilities. Child Care Health Dev 1997;23:41-6. 
32 Brach C, Fraser I. Can cultural competency reduce racial and ethnic health disparities? A review and conceptual model. Med Care Res Rev 2000;57(suppl 1):181-217

33 Stewart ALN-S, Perez-Stable A, Posner EJ, et al. Interpersonal processes of care in diverse populations. Milbank Q 1999;77:305-40.

34 Baker P, Mohieldeen Y. The languages of London's schoolchildren. In: Baker P, Eversley J, eds. Multilingual capital-the languages of London schoolchildren and their relevance to economic, social and educational policies. London: Battlebridge, 2000:5-60.

35 Storkey M. Using the schools' language data to estimate the total number of speaker of London's top 40 languages. In: Baker P, Eversley J, eds. Multilingual capital-the languages of London schoolchildren and their relevance to economic, social and educational policies. London: Battlebridge, 2000:63-6.

36 Carr-Hill R, Passingham S, Wolf A, et al. Lost opportunities: the language skills of linguistic minorities in England and Wales. London: Basic Skills Agency, 1996

37 Rudat K. Black and minority ethnic groups in England: health and lifestyles. London: Health Education Authority, 1994

38 Johnson MRD, Owen D, Blackburn C, et al. Black and minority ethnic groups in England: the second health and lifestyles survey. London: Health Education Authority, 2000.

39 Modood T, Berthoud R, Lakey J, et al. Ethnic minorities in Britain: diversity and disadvantage. London: Policy Studies Institute, 1997.

40 Hayes L. Unequal access to midwifery care: a continuing problem? J Adv Nurs 1995;21:702-7.

41 Baxter C. The case for bilingual workers within the maternity services. British Journal of Midwifery 1997;5:568-72.

42 Ehtisham M, Guthrie S, Hickling J, et al. Health needs of elderly people in the inner city. Birmingham: West Birmingham Health Authority, 1991

43 Lindesay J, Jagger C, Hibbett M, et al. Knowledge, uptake and availability of health and social services among Asian Gujarati and white elderly persons. Ethnicity and Health 1997;2:59-69.

44 Iqubal H. Palliative care service use by black and ethnic groups in Leicester. Leicester: Leicestershire Health, 1994.

45 Penso D, Hill D. Opening doors: improving access to hospice and specialist palliative care services by members of the black and ethnic minority communities. London: National Council for Hospice and Specialist Palliative Care Services, 1995.

46 Powell B. Improving accessibility and information services for Asian communities, relating to cancer and palliative care. Leicester: Cancer CareEthnic Minorities Group, 1999.

47 Modell B, Petrou M, Layton M, et al. Audit of prenatal diagnosis for haemoglobin disorders in the United Kingdom: the first 20 years. BMJ 1997; 315:779-85

48 Streetly A, Maxwell K, Mejia A. Sickle cell disorders in Greater London. A needs assessment of screening and care services. London: United Medical and Dental Schools Department of Public Health Medicine, 1997.

49 Dyson S. Genetic Screening and ethnic minorities. Critical Social Policy 1999;19:195-215.

50 Raja-Jones $\mathrm{H}$. Clinical. Breast screening and ethnic minority women: a literature review. British Journal of Nursing 1999;8:1284-8.

51 Lawrenson R, Leydon G, Freeman $G$, et al. Are we providing for ethnic diversity in accident and emergency (A\&E) departments? Ethnicity and Health 1998;3:117-23.

52 Leman P. Interpreter use in an inner city accident and emergency department. J Accid Emerg Med 1997; 14:98-100.

53 Shaw-Taylor Y, Benesch B. Workforce diversity and cultural competence in healthcare. J Cult Divers 1998;5:138-46.

54 Shaw-Taylor Y. Culturally and linguistically appropriate health care for racial or ethnic minorities: analysis of the US Office of Minority Health's recommended standards. Health Policy 2002;62:211-21.

55 Audit Commission. What seems to be the matter: communication between hospitals and patients. London: HMSO, 1994.

56 Jones J. Unaccompanied refugee children in Enfield and Haringey. London: publisher, 1999.

57 Hoare T. Breast screening and ethnic minorities. Br J Cancer 1996;74(suppl 29):S38-41.

58 Carr-Hill R, Rudat K. Unsound barrier. Health Services Journal 1995; 105:28-9.

59 Boomla K, Moser K, Naish J. Uptake of breast screening. Accurate addresses will improve uptake rates. BMJ 1995;310:1004.

60 Rudiman R, Gilbert FJ, Ritchie LD. Comparison of uptake of breast screening, cervical screening, and childhood immunisation. BMJ 1995;310:229.

61 Doyle Y. A survey of the cervical screening service in a London district, including reasons for non-attendance, ethnic responses and views on the quality of the service. Soc Sci Med 1991;32:953-7.

62 Majeed FA. Using patient and general practice characteristics to explain variations in cervical smear uptake rates. BMJ 1994;308:1272-6.

63 Box V. Cervical screening: the knowledge and opinions of black and minority ethnic women and of health advocates in East London. Health Education Journal 1998;57:3-15.

64 Chiu LF. Balancing the equation: the significance of professional and lay perceptions in the promotion of cervical screening amongst minority ethnic women. Critical Public Health 1999;9:5-22.

65 Majeed FA, Cook DG, Given-Wilson R, et al. Do general practitioners influence the uptake of breast cancer screening? J Med Screen 1995;2:119-24.

66 Hoare TA. Reasons for non-attendance for breast screening by Asian women. Health Education Journal 1992;51:157-61.
67 Botha JL, Manku-Scott TK, Moledina F, et al. Indirect discrimination and breast screening. Ethn Dis 1993;3:189-95

68 Sutton S, Bickler G, Sancho-Aldridge J, et al. Prospective study of predictors of attendance for breast screening in inner London. J Epidemiol Community Health 1994:48:65-73.

69 Bradley SN, Friedman EH. Cervical cytology screening: a comparison of uptake among 'Asian' and 'non-Asian' women in Oldham. J Public Health Med 1993; 15:46-51

70 Sutton GC, Storer A, Rowe K. Cancer screening coverage of south Asian women in Wakefield. J Med Screen 2001;8:183-6.

71 McAvoy B, Raza R. Can health education increase uptake of cervical smear test among Asian women? BMJ 1991;302:833-6.

72 Majeed A, Given-Wilson R, Smith E. Impact of follow up letters on nonattenders for breast screening: a general practice based study. J Med Screen 1997:4:19-20.

73 Atri J, Falshaw M, Gregg R, et al. Improving uptake of breast screening in multiethnic populations: a randomised controlled trial using practice reception staff to contact non-attenders. BMJ 1997;315:1356-9.

74 Sharp DJ, Peters TJ, Bartholomew J, et al. Breast screening: a randomised controlled trial in UK general practice of three interventions designed to increase uptake. J Epidemiol Community Health 1996;50:72-6.

75 Hoare T, Thomas C, Biggs A, et al. Can the uptake of breast screening by Asian women be increased? A randomized controlled trial of a linkworker intervention. J Public Health Med 1994:16:179-85.

76 Falshaw ME, Fenton C, Parsons L, et al. Improving the uptake of breast screening: one initiative in east London. Public Health 1996;1 10:305-6

77 Navarro AM, Senn KL, Kaplan RM, et al. Por La Vida intervention model for cancer prevention in Latinas. Monogr Natl Cancer Inst 1995;18:137-45.

78 Sung JFC, Coates RJ, Williams JE, et al. Cancer screening intervention among Black women in inner-city Atlanta-design of a study. Public Health Rep 1992; 107:381-8.

79 Del Mar C, Glasziou P, Adkins P, et al. Do personalised letters in Vietnamese increase cervical cancer screening among Vietnamese women? A randomised controlled trial. N Z J Public Health 1998;22:824-5.

80 Hunt JM, Lawton GG, Straton JAY. Pap smear screening at an urban aboriginal health service: report of a practice audit and an evaluation of recruitment strategies. Aust N Z J Public Health 1998;22:720-5.

81 Bell TS, Branston LK, Newcombe RG, et al. Interventions to improve uptake of breast screening in inner city Cardiff general practices with ethnic minority lists. Ethnicity and Health 1999;4:277-84.

82 Kernohan EE. Evaluation of a pilot study for breast and cervical cancer screening with Bradford's minority ethnic women; a community development approach, 1991-93. Br J Cancer Suppl 1996;29:S42-6.

83 Cancer Research UK. http://www.cancerresearchuk.org/aboutcancer/ statistics/mortality (accessed 19 Nov 2003)

84 Garvican L. Planning for a possible national colorectal cancer screening programme. J Med Screen 1998;5:187-94.

85 Hardcastle JD, Chamberlain JO, Robinson ME, et al. Randomised control trial of faecal occult blood screening for colorectal cancer. Lancet 1996;348: 1472-7.

86 Verne JE, Aubrey R, Love SB, et al. Population based randomized study of uptake and yield of screening by flexible sigmoidoscopy compared with screening by faecal occult blood testing. BMJ 1998;317:182-5.

87 Hoffman-Goetz L, Breen NL, Meissner H. The impact of social class on the use of cancer screening within three racial/ethnic groups in the United States. Ethn Dis 1998:8:43-51.

88 Lindholm E, Berglund B, Haglind E, et al. Factors associated with participation in screening for colorectal cancer with faecal occult blood testing. Scand J Gastroenterol 1995;30:171-6.

89 Boring C, Squires T, Heath C. Cancer statistics for African Americans. CA Cancer J Clin 1992:42:7-17.

90 Weinrich S. Predictors of older adults' participation in fecal occult blood screening. Oncol Nurs Forum 1990;17:715-20.

91 American Cancer Society. Cancer in the socioeconomically disadvantaged. Atlanta: American Cancer Society, 1990.

92 South Carolina Task force on Minority Health. Closing the gap: a call for action. Columbia: SC Department of Health and Environment Control, 1990

$93 \mathrm{Kim} \mathrm{K}, \mathrm{Yu}$ ES, Chen EH, et al. Colorectal cancer screening. Knowledge and practices among Korean Americans. Cancer Practice 1998;6:167-75.

94 Tang TS, Solomon L, McCracken LM. Barriers to fecal occult blood testing and sigmoidoscopy among older Chinese-American women. Cancer Practice $2001 ; 9: 277-82$.

95 Yu ESH, Kim KK, Chen EH, et al. Colorectal cancer screening among Chinese Americans: a community-based study of knowledge and practice. Journal of Psychosocial Oncology 2001;19:97-112.

96 Beeker C, Kraft JM, Goldman R, et al. Strategies for increasing colorectal cancer screening among African Americans. Journal of Psychosocial Oncology 2001;19:113-32.

97 Douglas CY. Community-based screening interventions for colorectal cancer. Journal of Psychosocial Oncology 2001;19:133-46.

98 Szczepura A, Johnson M, Orbell S, et al. Addressing ethnic diversity: key findings from the UK colorectal cancer screening pilot. London: Department of Health, 2003

99 Powe BD. Fatalism among elderly African Americans. Effects on colorectal cancer screening. Cancer Nurs 1995;18:385-92.

100 Theuer CP, Taylor TH, Brewster WR, et al. The topography of colorectal cancer varies by race/ethnicity and affects the utility of flexible sigmoidoscopy. Am Surg 2001;67:1157-61.

101 Thever CP, Wagner JL, Taylor TH, et al. Racial and ethnic colorectal cancer patterns affect the cost-effectiveness of colorectal cancer screening in the United States. Gastroenterology 2001; 120:848-56. 